\title{
Myositis Ossificans of the Masseter Muscle
}

Sir,

Myositis ossificans (MO) is a form of heterotopic ossification in which metaplastic calcification and successive ossification takes place within the muscle tissue. MO progressiva and MO traumatica (MOT) are the two variants of MO. MOT is caused by a traumatic event and is most commonly associated with muscles of the hip, anterior thigh and anterior arm. ${ }^{[1]}$ Recently, Boffano $e t$ al..$^{[2]}$ found that of the 42 cases of MOT involving masticatory muscles reported in the literature, 25 cases involved the masseter muscle. ${ }^{[2]}$

A 36-year-old male presented with a complaint of restricted mouth opening for the past 3 months to the Department of Oral Medicine and Radiology at Tamil Nadu Government Dental College and Hospital. The patient had a history of trauma due to fall, which resulted in swelling on the left side of his face. The swelling was initially firm, but gradually hardened over a period. On examination, a diffuse, hard, nontender swelling measuring approximately $5 \times 3 \mathrm{~cm}$ was found. The swelling was palpable in continuation with the left masseter muscle when the patient was asked to clench his teeth. The patient's mouth opening was restricted to $2 \mathrm{~mm}$ [Figure 1a].

Panoramic radiograph revealed a quadrilateral radiopacity attached to zygomatic arch extending posteroinferiorly toward the ramus of mandible. A computed tomography (CT) scan showed evidence of hypertrophy of left masseter muscle and intramuscular mass, with a rim of peripheral ossifications and a low-density central area attached at the left zygomatic arch and ramus [Figure 2]. A CT three-dimensional volumetric reconstruction showed a solitary, irregular calcified mass extending posteroinferiorly from the inferior border of the zygomatic arch to the ramus, following the masseter muscle anatomy. The patient's serum calcium, serum phosphorus and

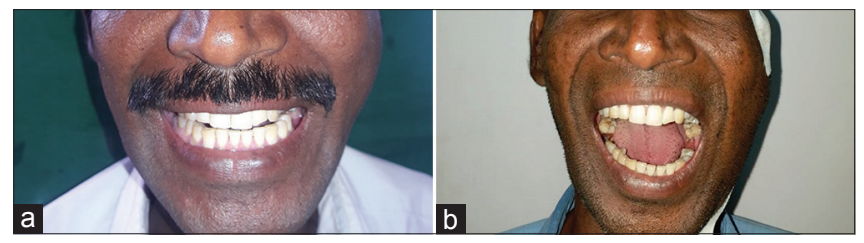

Figure 1: (a) Image showing a swelling present over the left side of the patient's face and severe trismus with maximum mouth opening restricted to $2 \mathrm{~mm}$; (b) Post-treatment photograph of the patient with sufficient mouth opening alkaline phosphatase values were within normal limits. Based on the findings, a diagnosis of MOT of the left masseter muscle was made. The ossified mass was excised under general anesthesia, and a mouth opening of $30 \mathrm{~mm}$ was achieved [Figure 1b]. Histopathologic examination of the excised mass revealed mature lamellar bone correlating with late-stage MO.

Pain, tenderness and a soft-tissue mass are the most common symptoms of MOT. In terms of MOT of masticatory muscles, trismus is the most common symptom. ${ }^{[3]} \mathrm{MO}$ has three characteristic phases, namely, acute, subacute and maturation phases, leading to the so-called "zone phenomenon" during its development. Magnetic resonance imaging (MRI) scans can help identify the zone phenomenon before ossification appears. On T1- and T2-weighted MRI scans, isointensity and slight hyperintensity can be observed, respectively. Rim enhancement is seen in the acute phase of MO. In the subsequent subacute and maturation phases, the rim appears hypointense on all MRI sequences, indicating mineralization. The standard radiographs fail to disclose radiographic changes in the initial stages of $\mathrm{MO}$, but during the later stages, they may show evidence of ossification. However, a CT scan has higher sensitivity in detecting ossification than plain radiography. A CT scan may also show a central fatty metaplastic area. ${ }^{[4]}$

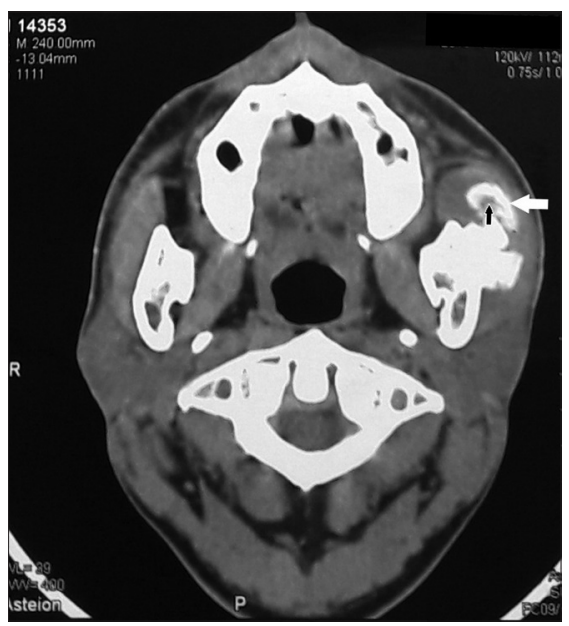

Figure 2: Computed tomography axial section showing hypertrophy of the left masseter muscle and a calcified mass attached to left ramus of the mandible (intramuscular mass with peripheral ossifications [white arrow] and a low-density central area indicating fatty metaplastic transformation [black arrow]) 
MO can be mistaken clinically or histologically for a malignant tumor. Ossification pattern and histopathological appearance help differentiate MO from osteosarcoma. Ossifications in $\mathrm{MO}$ are peripheral and centripetal, whereas in osteosarcoma, they are central and centrifugal. Histopathologically, MO shows the zone phenomenon and a lack of invasion to adjacent tissues, while in osteosarcoma, destruction of viable muscle fibers is seen ${ }^{[5]}$ Both surgical and nonsurgical treatments are available for MOT. Surgical intervention includes excision of the ossified mass followed by extensive physiotherapy. Nonsurgical treatments include nonsteroidal anti-inflammatory drugs, magnesium, bisphosphonates and warfarin; low-dose radiation therapy; immobilization; ice; elevation; ultrasound; cold laser; and iontophoresis. ${ }^{[6]}$

\section{Declaration of patient consent}

The authors certify that they have obtained all appropriate patient consent forms. In the form, the patient has given his consent for his images and other clinical information to be reported in the journal. The patient understands that his names and initials will not be published, and due efforts will be made to conceal their identity, but anonymity cannot be guaranteed.

\section{Financial support and sponsorship}

Nil.

\section{Conflicts of interest}

There are no conflicts of interest.

\section{Kayal, G. V. Murali Gopika Manoharan, Bhaumik Joshi}

Department of Oral Medicine and Radiology, Tamil Nadu Government Dental College and Hospital, Affiliated with Tamil Nadu Dr. MGR Medical University, Chennai, Tamil Nadu, India
Address for correspondence: Dr. Bhaumik Joshi, Department of Oral Medicine and Radiology, Tamil Nadu Government Dental College and Hospital, Affiliated with Tamil Nadu Dr. MGR Medical University, Chennai - 600 003, Tamil Nadu, India.

E-mail: drbjoshi11@gmail.com

\section{REFERENCES}

1. King JB. Post-traumatic ectopic calcification in the muscles of athletes: A review. Br J Sports Med 1998;32:287-90.

2. Boffano P, Zavattero E, Bosco G, Berrone S. Myositis ossificans of the left medial pterygoid muscle: Case report and review of the literature of myositis ossificans of masticatory muscles. Craniomaxillofac Trauma Reconstr 2014;7:43-50.

3. Dhanrajani PJ, Jonaidel O. Trismus: Aetiology, differential diagnosis and treatment. Dent Update 2002;29:88-92, 94.

4. Lacout A, Jarraya M, Marcy PY, Thariat J, Carlier RY. Myositis ossificans imaging: Keys to successful diagnosis. Indian J Radiol Imaging 2012;22:35-9.

5. Goldman AB. Myositis ossificans circumscripta: A benign lesion with a malignant differential diagnosis. AJR Am J Roentgenol 1976;126:32-40.

6. Thangavelu A, Vaidhyanathan A, Narendar R. Myositis ossificans traumatica of the medial pterygoid. Int J Oral Maxillofac Surg 2011;40:545-9.

This is an open access journal, and articles are distributed under the terms of the Creative Commons Attribution-NonCommercial-ShareAlike 4.0 License, which allows others to remix, tweak, and build upon the work non-commercially, as long as appropriate credit is given and the new creations are licensed under the identical terms.

\begin{tabular}{|l|l|}
\hline \multicolumn{2}{|c|}{ Access this article online } \\
\hline Quick Response Code: & Website: \\
\hline & www.sjmms.net \\
\cline { 2 - 2 } & DOI: \\
\hline
\end{tabular}

How to cite this article: Kayal L, Manoharan GV, Joshi B. Myositis ossificans of the masseter muscle. Saudi J Med Med Sci 2018;6:119-20.

@ 2018 Saudi Journal of Medicine \& Medical Sciences | Published by Wolters Kluwer - Medknow 